\title{
Four facets of Facebook Intensity - The development of the Multidimensional Facebook Intensity Scale
}

Article in Personality and Individual Differences · November 2015

DOI: $10.1016 /$ j.paid.2015.11.038

CITATION

1

3 authors:

Orosz Gábor

Hungarian Academy of Sciences

48 PUBLICATIONS 38 CITATIONS

SEE PROFILE

Beáta Bőthe

Eötvös Loránd University

18 PUBLICATIONS 9 CITATIONS

SEE PROFILE
István Tóth-Király

Eötvös Loránd University

20 PUBLICATIONS 10 CITATIONS

SEE PROFILE 


\title{
Four facets of Facebook intensity - The development of the Multidimensional Facebook Intensity Scale is
}

\author{
Gábor Orosz ${ }^{\mathrm{a}, \mathrm{b}, *}$, István Tóth-Király ${ }^{\mathrm{a}}$, Beáta Bőthe ${ }^{\mathrm{a}}$ \\ a Institute of Psychology, Eötvös Loránd University, Budapest, Hungary \\ ${ }^{\mathrm{b}}$ Hungarian Academy of Sciences Research Centre for Natural Sciences, Institute of Cognitive Neuroscience and Psychology, Budapest, Hungary
}

\section{A R T I C L E I N F O}

Article history:

Received 21 April 2015

Received in revised form 6 November 2015

Accepted 17 November 2015

Available online $\mathrm{xxxx}$

\section{Keywords:}

Facebook intensity

Facebook persistence

Facebook self-expression

Facebook overuse

Facebook boredom

ESEM

CFA

\begin{abstract}
A B S T R A C T
The aim of the present study was to create a short and valid questionnaire: the Multidimensional Facebook Intensity Scale (MFIS). In Study $1(\mathrm{~N}=512)$, we used exploratory structural equation modeling to explore the basic dimensions of everyday Facebook use. The results suggested four factors: persistence, boredom, overuse, and self-expression. The MFIS also had good reliability in terms of internal consistency and temporal stability. In Study $2(\mathrm{~N}=566)$, confirmatory factor analysis was conducted in order to assess the factor structure revealed in the previous study. The four-factor first-order and the second order model appeared to be adequate contrasting to the one factor model. Based on target coefficient the four-factor second-order model appears to be the most adequate. In Study $3(\mathrm{~N}=531)$, the convergent validity of the MFIS was examined in relation to Facebook addiction, Facebook passion, Online Sociability and different personality dimensions. The MFIS can predict Facebook-related activities as liking and posting better than previous Facebook scales. The results suggest that this questionnaire is able to reliably differentiate between different aspects of Facebook use intensity.
\end{abstract}

(c) 2015 Elsevier Ltd. All rights reserved.

\section{General introduction}

People spend a lot of time on Facebook. The number of daily users is 890 million who spend 21 min on Facebook on average. From these two numbers, we can calculate that users spend 35,559 years on Facebook every day. If we paid 5 USD for $1 \mathrm{~h}$ of Facebook use, it would cost $1,557,500,000$ USD per hour. Facebook is valuable, not only in a financial sense, but it has other more overarching values in the everyday life of the users who differ concerning how they are related to Facebook. In the present study, we intend to explore these individual differences by measuring self-reported Facebook use intensity and attitudes towards it in a more specific way than before.

Facebook use can be measured with different self-reported measures. At the dawn of Facebook research, these scales focused on the time one passed on Facebook (per day or week), the number of Facebook friends, Facebook group memberships, and some of the Facebook activities as reading and writing posts by using unidimensional measures (e.g. Bijari, Javadinia, Erfanian, Abedini, \& Abassi, 2013; Kirschner \& Karpinski, 2010). Firstly, Ellison, Steinfield, and Lampe (2007) measured Facebook intensity in terms of Facebook attitudes which go beyond the above-mentioned aspects.

\footnotetext{
it All authors contributed equally to this paper.

* Corresponding author at: Institute of Psychology, Eötvös Loránd University, Izabella utca 46, Budapest H-1064, Hungary.

E-mail address: orosz.gabor@ttk.mta.hu (G. Orosz).
}

They intended to grasp the magnitude Facebook is integrated in respondents' everyday life (with items as "Facebook is part of my everyday activity" or "I would be sorry if Facebook shut down"). This scale has some items which are less informative eight years later in those countries where Facebook has become widespread (i.e. "I feel I am part of the Facebook community.") This scale provided the basis of many further studies (Cavallo et al., 2012; Kalpidou, Costin, \& Morris, 2011; Kwan \& Skoric, 2013) and several attempts were made to complement or modify it (Glynn, Huge, \& Hoffman, 2012; Ross et al., 2009).

Afterwards, Joinson (2008) made a multidimensional Facebook use scale on the basis of qualitative data by using open-ended questions referring to the motivation of Facebook use. He identified seven dimensions as social connection, shared identities, photographs, content, social investigation, social network surfing, status updates. One year later, Pempek, Yermolayeva, and Calvert (2009) investigated Facebook use by focusing on the time users spend on Facebook and concerning their activities on the site (chat, photo upload, sharing). Finally, participants of this study filled out a 54-item questionnaire referring to their last week Facebook activity. In this case the authors did not identify clearly distinctive factors concerning Facebook use.

Several questionnaires were created to measure Facebook motivations. They are mainly oriented towards why someone uses Facebook instead of measuring Facebook use intensity. Aladwani (2014) created a 34-item questionnaire which has eight factors referring to the different motivations of Facebook use. These factors were the following: connecting, sharing, relaxing, branding, organizing, monitoring, 
expressing, and learning. This comprehensive model grasps the main motivational dimensions of Facebook use. However, it did not refer to the Facebook use characteristics or Facebook attitudes directly and it had weaknesses in terms of factor structure. Ross et al. (2009) created a 28-item questionnaire which has three factors (general Facebook use, attitudes towards Facebook, online sociability) without unified response options. This scale also has methodological shortcomings. Furthermore, Mazman and Usluel (2010) created a motivational Facebook scale which basically focused on Facebook activities and its educational aspects. This scale has good factor structure, but it has a narrowed scope of the scale in terms of education.

In sum, concerning Facebook use, previously mainly unidimensional measures were implemented in research. In the field of Facebook motivation, several attempts were made in order to create a psychometrically appropriate scale which can grasp all relevant dimensions. Only a very few of them has good factor structure (Mazman \& Usluel, 2010) or appropriate internal consistencies (Aladwani, 2014). However, in the case of Facebook intensity, as far as we know, there is no available multidimensional measure. The Facebook Intensity Scale (Ellison et al., 2007) was created almost a decade ago and it has been a short and appropriate measure until recently because it grasps not only the time one spends on Facebook or the number of friends but the strength of involvement in Facebook activities. However, after almost one decade it might be useful to reexamine the Facebook use intensity and focus on its multifaceted nature.

Facebook intensity can be distinguished from Facebook habits-time spent on Facebook, number of Friends, and number of group memberships-because the latter does not necessarily reflect on the emotional connectedness to Facebook use. One may spend hours on Facebook passively or one may have 4000 friends with several group memberships, but it does not necessarily highlight the given person's involvement in Facebook. Studies examining such Facebook habits may not uncover the emotional bond between the individual and Facebook (Aghazamani, 2010; Alhabash, Park, Kononova, Chiang, \& Wise, 2012; Bijari et al., 2013; Kirschner \& Karpinski, 2010; Mazman \& Usluel, 2010; Rosen, Carrier, \& Cheever, 2013; Ross et al., 2009). Therefore, we assume that the notion of Ellison et al. (2007) can uncover deeper layers of Facebook involvement and the reexamination of the facets might be relevant considering changes of Facebook and the huge number of diverse users who integrated Facebook use into their everyday life.

We distinguish Facebook intensity from motivations (Aladwani, 2014; Bijari et al., 2013; Joinson, 2008; Mazman \& Usluel, 2010; Pempek et al., 2009; Sheldon, 2008; Smock, Ellison, Lampe, \& Wohn, 2011; Tosun, 2012; Yang \& Brown, 2013). Motivations mainly reflect on why one uses Facebook, while Facebook intensity grasps the level of involvement in Facebook use. It is possible that one has several motivations to use Facebook, but the given person will use it with low intensity. Furthermore, it is possible that one has a unique motivation, but the Facebook intensity will be high.

We distinguish Facebook addiction from Facebook intensity in terms of pathology: Facebook intensity is not necessarily a problematic behavior, however it is not true for Facebook addiction (Andreassen, Torsheim, Brunborg, \& Pallesen, 2012; Masur, Reinecke, Ziegele, \& Quiring, 2014). We assume that they are positively related, but supposedly, the prerequisite of Facebook addiction is high Facebook intensity, but not the other way around: Facebook addiction is not the prerequisite of Facebook intensity.

In sum, several aspects of Facebook use have been examined thoroughly. However, as it has been demonstrated, Facebook intensity goes beyond these aspects of use. It refers to the strength of involvement in the activity itself and it intends to grasps the magnitude of the integration of Facebook into one's everyday life. This construct complements the previous ones (habits, motivations, addiction). However, in the new era of Facebook-by following the footsteps of Ellison et al.'s (2007)-it might be timely to discover the facets of Facebook intensity.

As several new features have been added and built into Facebook, more and more people find it useful to integrate it into their lives. For instance, it is possible to use Facebook as a "workplace" or as a marketing tool. The "Events" function can be used to arrange appointments, meetings, or concerts. Also, it can have relevance in education: study groups can be created to help a teacher in managing classes. Facebook has become one of the most important group organizing and maintaining platforms among co-workers, friends and those who have similar hobbies. Moreover, it could facilitate the communication between the members of formal and informal groups. Facebook users can also play games. This multifaceted usability can lead to more diverse psychological relatedness to Facebook than it was previously conceptualized by Ellison et al. (2007). Therefore, different aspects of Facebook intensity might deserve scientific investigation.

Based on previous studies, the goal of the present research was the creation of a comprehensive Multidimensional Facebook Intensity Scale (MFIS) which (a) can measure the most important facets of Facebook use, (b) which is short, and (c) which has good psychometric properties both in terms of validity, internal consistency and temporal stability.

\subsection{Overview of the studies}

In the following studies, we intended to establish the most important dimensions of normal Facebook use. In Study 1, we used exploratory structural equation modeling to identify the facets of Facebook intensity and we measured the temporal stability of the identified scales. In Study 2, we performed confirmatory factor analysis to confirm its factor structure. In Study 3, we investigated its convergent validity with other variables measuring Facebook use and basic personality traits. In Study 4 we investigated incremental validity of MFIS compared to a previous Facebook Intensity Scale regarding self-reported Facebook behaviors.

\section{Study 1}

Similar to Ellison et al. (2007), we interpret Facebook intensity-regarding all dimensions of the MFIS-as attitudes which refer to the emotional connectedness to Facebook and we intended to create such items which can reliably measure how much Facebook is integrated into the everyday activities of the given individual. We aimed to create a scale which is relevant to general Facebook users, and which does not focus on the pathologic or addiction-related aspects of Facebook use. On the basis of previous studies, we identified four main facets of Facebook use which can describe the intensity of Facebook use of a given individual.

The first factor refers to the users' persistence to use Facebook. Those who have high score on this dimension check Facebook before going to bed and for them Facebook is one of the most important sites on the Internet. These individuals look for Internet connection in order to access Facebook. In the case of Facebook persistence, an emotional bond is established between the given person and Facebook. We do not assume that Facebook persistence is necessarily related to very positive affects towards Facebook or that those users see Facebook use as wasting time (Giannakos, Chorianopoulos, Giotopoulos, \& Vlamos, 2013). Persistence includes mainly affective and behavioral aspects. The affective dimension is related to negative feelings if Facebook is not available for the user, while checking it before going to bed or looking for Internet access for using Facebook is mainly related to the behavior dimension. We assume that persistence reflects on a solid Facebook use habit.

The second factor refers to the individual's goal to use Facebook in order to relieve boredom. In previous studies (e.g. Lampe, Ellison, \& Steinfield, 2008; Pempek et al., 2009), fighting boredom or passing time was one of the motivations that contributed to the intensive use 
of Facebook. Since Facebook can provide many different stimuli, it can be an ideal place to pass time when the individual is bored. This factor also includes both affective and behavioral aspects. Boredom is a negative and low arousal emotion which can be related to intensive Facebook use.

The third facet was named Facebook overuse. This factor indicates that an individual logs into Facebook even if (s)he does not have time, thus uses it intensively. This dimension focuses on the excessive use of Facebook perceived by the user who noticed the problems related to Facebook use. However, we intended to formulate the related items which are relevant to a significant part of the users and not only to that minority who have severe consequences or serious problems because of Facebook use. Therefore, Facebook overuse can be placed on the edge of pathologic and non-pathologic Facebook use, dissimilar to Facebook addiction (Andreassen et al., 2012) which intends to focus on the pathologic side.

The fourth factor indicates users' self-expression on Facebook. Many studies (Aladwani, 2014; Alhabash et al., 2012; Christofides, Muise, \& Desmarais, 2009; Mehdizadeh, 2010; Strano, 2008) have also identified profile-related activities as a possible indicator of Facebook use. Through a detailed and updated profile page, users can express their own ideas, likings and style to other users. This profile page functions as an "online business card" which can be updated as often as the user wants it. The relatively frequent use of Facebook and the high number of acquaintances on Facebook can give possibilities to different forms of impression management. It also has affective and behavioral aspects in terms of preferring the profile adjustments and the frequency of doing so. In the first study, we intended to preselect those items which can grasp the above-mentioned four facets of Facebook use with exploratory structural equation modeling.

\subsection{Methods}

\subsubsection{Item construction}

On the basis of a focus group, 20 items were created by in order to measure the intensity of Facebook use. The group consisted of 18 university students ( 3 males, 15 females, $M_{\text {age }}=20.72 ; S D_{\text {age }}=2.10$ ) who had a Facebook account. We formed four groups of the students and they were asked about all of the four Facebook facets which provided the basis of the wording of the items. On the basis of the focus groups, the authors wrote items which were aimed to be less than 10 words, which were very easy to understand, which clearly belonged to the factors, and which had good face validity. We created five items for each factors. In a second session, these items were reviewed and revised in a group meeting where a professor and the 18 university students were present. As a result of an in-depth discussion with the group, seven items were dropped before data gathering as a consequence of lack of clarity, or unclear factor belongingness. Three items were dropped as a result of the lack of clarity (i.e. I'm one of those persons who post on Facebook what I do, when I do, with whom I do.), and four as a consequence of the unclear factor belongingness (i.e. Most frequently I receive news through Facebook.).

\subsubsection{Participants, measures and procedure}

A total of 512 participants ( $64 \%$ female) between the age of 18 and 41 filled out the questionnaire $\left(M_{\text {age }}=22.11 ; S D_{\text {age }}=2.43\right)$. Respondents spent 15.69 years ( $S D=1.95$ years) in the educational system. The Multidimensional Facebook Intensity Scale (MFIS) contained 13 items in which respondents had to indicate their level of agreement to the items on a five-point Likert-scale ( $1=$ strongly disagree; $2=$ disagree; $3=$ neither agree nor disagree; $4=$ agree; $5=$ strongly agree). For assessing temporal stability of the scales, 93 participants filled out the questionnaire $\left(F=66, M_{a g e}=22.67, S D_{a g e}=5.04\right)$ over a four week period.

The study was conducted in accordance with the Declaration of Helsinki and was approved by the ethical board of the related university.
The research was conducted with an online questionnaire system, the filling out lasted approximately $3 \mathrm{~min}$. First, participants were informed about the goal and the content of the study, then they were asked to check a box if they agreed to continue and participate. They were assured about their anonymity. The first part of the questionnaire contained questions regarding demographic data, such as gender, age and level of education. They were also asked to estimate the amount of time they spend using the Internet on an average weekend and weekday. Similar questions were asked regarding their Facebook use. In the last part, the items of the MFIS were presented.

\subsubsection{Statistical analysis}

Exploratory structural equation modeling (ESEM) was used with maximum-likelihood estimation (ML) and Geomin oblique rotation with Mplus 7.3 (Muthén \& Muthén, 1998-2012). Compared to the exploratory factor analysis, ESEM is considered to be preferable as it (1) allows the items to cross-load, (2) allows the exploratory testing of different factor structures, and (3) allows the direct comparison of the exploratory and confirmatory analyses (Asparouhov \& Muthén, 2009). When assessing the model fit, several indices can be taken into consideration (Brown, 2006): the Comparative Fit Index (CFI), the TuckerLewis Index (TLI), the root mean square error of approximation (RMSEA), its $90 \%$ confidence interval $(90 \% \mathrm{CI})$, the test of close fit (CFit), and the standardized root mean square residual (SRMR). Additionally, the Akaike Information Criterion (AIC) and the Bayesian Information Criterion (BIC) were calculated to compare the alternative models. Following the suggestions of $\mathrm{Hu}$ and Bentler (1999), a model was considered acceptable if it reached the following thresholds: CFI $(\geq .95)$, TLI ( $\geq .95)$, RMSEA $(\leq .06)$, CFit $(\geq .05, n s)$; and SRMR $(\leq .08)$. The AIC and the BIC do not have a clear cut-off point; the lower the value the better the model fit is. Internal consistency was also assessed with Cronbach's alpha where the threshold of acceptability was .70 (Nunnally, 1978). The normality thresholds for skewness and kurtosis were required to be between -1 and +1 when assessing normality.

\subsection{Results}

Table 1 includes the main results of Study 1 . The final model-with 4 factors and 13 items-showed good model fit [CFI $=.98$; TLI $=.96$; RMSEA $=.05,90 \%$ CI .03-.06; CFit $=.52$; SRMR $=.02$; AIC $=19,371$; $\mathrm{BIC}=19,676]$. Factor loadings ranged from .48 to .83 , no item had smaller factor loading than .32, and the highest cross-loading was .25. The four factors had good reliabilities in terms of factor determinacy, internal consistency, and temporal stability. Correlations between the factors were moderate and significant, ranging from .27 to .50 (see Table 2).

According to the results, all the 13 items were loaded on the expected four factors-without high cross-loadings-indicating an appropriate factor structure. The skewness and kurtosis values are between -1 and 1 which indicates that the distribution of the responses is close to normal. Furthermore, the scale appears to be reliable both in terms of internal consistency and temporal stability (Table 1). The Facebook intensity facets show small to medium correlations with each other (Table 2). In the following step, we intended to examine the explored factor structure with confirmatory factor analysis (CFA).

\section{Study 2}

The purpose of the second study was to examine whether the factor structure demonstrated in Study 1 show acceptable model fit by using CFA. Three models were tested: first, a first-order model where all items loaded on one single general factor (Facebook intensity) which would mean that all items represent this one dimension and in this case, it could be assumed that Facebook use intensity is a unidimensional concept. Second, another first-order model was tested with the four factors demonstrated in Study 1; it would indicate that Facebook 
Table 1

Results of the exploratory structural equation modeling on the Multidimensional Facebook Intensity Scale items.

\begin{tabular}{|c|c|c|c|c|}
\hline & \multicolumn{4}{|c|}{ Multidimensional Facebook Intensity Scale factors } \\
\hline & Persistence & Boredom & Overuse & Self-expression \\
\hline 1. If I could visit only one site on the Internet, it would be Facebook. & .62 & .02 & -.05 & .01 \\
\hline 5. I feel bad if I don't check my Facebook daily. & .65 & -.01 & .02 & .03 \\
\hline 9. I often search for Internet connection in order to visit Facebook. & .64 & -.03 & .06 & .09 \\
\hline 13. Before going to sleep, I check Facebook once more. & .59 & .18 & -.01 & -.04 \\
\hline 2. Watching Facebook posts is good for overcoming boredom. & -.01 & .54 & -.02 & .19 \\
\hline 6. When I'm bored, I often go to Facebook. & -.02 & .82 & .12 & .00 \\
\hline 10. If I'm bored, I open Facebook. & .10 & .83 & -.01 & .01 \\
\hline 3. I spent time on Facebook at the expense of my obligations. & -.03 & -.05 & .80 & .05 \\
\hline 7. I spend more time on Facebook than I would like to. & .04 & .16 & .56 & -.06 \\
\hline 11. It happens that I use Facebook instead of sleeping. & .34 & .05 & .48 & .01 \\
\hline 4. My Facebook profile is rather detailed. & .02 & -.01 & -.01 & .69 \\
\hline 8. I like refining my Facebook profile. & -.03 & .05 & -.03 & .83 \\
\hline 12. It is important for me to update my Facebook profile regularly. & .08 & -.02 & .12 & 73 \\
\hline Factor determinacy & .89 & .93 & .87 & .91 \\
\hline Cronbach's alpha & .75 & .81 & .72 & .80 \\
\hline Skewness (SD) & $.55(.11)$ & $-.17(.11)$ & $.23(.11)$ & $.78(.11)$ \\
\hline Kurtosis (SD) & $-.45(.22)$ & $-.72(.22)$ & $-.95(.22)$ & $-.07(.22)$ \\
\hline Test-retest correlation & .87 & .80 & .80 & .82 \\
\hline
\end{tabular}

Factor loadings $>.4$ are in bold.

intensity can be grasped along these four dimensions. Third, a secondorder model was examined where there is a hierarchical factor behind the four intensity dimensions. In this case, the four factors represented one higher factor, Facebook intensity. The second order model could allow the use of total scores of Facebook intensity and their four subscores separately.

\subsection{Methods}

\subsubsection{Participants and procedure}

For the confirmatory factor analysis, $596(F=383)$ participants, aged between 14 and 67 years filled out the 13-item questionnaire of the first study. Thirty respondents were excluded from the analyses, because they did not reach the necessary age-limit of 18 years. Therefore, $566(F=363)$ respondents remained in the study $(M=24.21 ; S D=$ 8.12) All factors showed good reliability in terms of Cronbach's alpha value $\left(\alpha_{\text {persistence }}=.77 ; \alpha_{\text {boredom }}=.84 ; \alpha_{\text {overuse }}=.71 ; \alpha_{\text {self-expression }}=\right.$ $.77)$ and factor determinacy ( $\mathrm{FD} ; \mathrm{FD}_{\text {persistence }}=.92 ; \mathrm{FD}_{\text {boredom }}=.94$; $\left.\mathrm{FD}_{\text {overuse }}=.89 ; \mathrm{FD}_{\text {self-expression }}=.90\right)$. The study was carried out with the approval of the Institutional Review Board of the related university and was done in accordance with the Declaration of Helsinki.

\subsubsection{Statistical analysis}

Confirmatory factor analyses (CFA) were performed using Mplus 7.3 (Muthén \& Muthén, 1998-2012) with maximum-likelihood estimation (ML). The same fit indices with the same cut-off values have been applied here as in Study 1. Additionally, when comparing the first- and the second-order models, the target coefficient $(\mathrm{T})$ has been calculated as suggested by Marsh and Hocevar (1985). It is the ratio of the chisquare value of the first-order model to the chi-square value of the second-order model. This value can have a maximum of one and higher values suggest that the second-order factor (Facebook intensity) can adequately explain the covariance between the first-order factors.

Table 2

Correlations between the factors of the Multidimensional Facebook Intensity Scale.

\begin{tabular}{lllll}
\hline & Boredom & Persistence & Self-expression & Overuse \\
\hline Boredom & - & & & \\
Persistence & $.50^{*}$ & - & & \\
Self-expression & $.31^{*}$ & $.43^{*}$ & - & - \\
Overuse & $.44^{*}$ & $.45^{*}$ & $.27^{*}$ & - \\
\hline
\end{tabular}

* $p<.01$.

\subsection{Results}

Table 3 includes the comparison of alternative models of the MFIS. In order to examine the factor structure of this new measurement, CFA was performed based on the results of Study 1. First, a single-factor solution was tested where all items loaded on one single factor. Fit indices indicated bad fit $[\mathrm{CFI}=.75$; TLI $=.69$; RMSEA $=.14,90 \% \mathrm{CI} .13-.15$; CFit $=.000 ;$ SRMR $=.08 ;$ AIC $=21,898 ;$ BIC $=22,067]$. This result supports the hypothesized multidimensionality of the MFIS against the notion of unidimensionality.

Next, the first-order solution with four factors was tested and it demonstrated good fit [CFI $=.96$; TLI $=.95$; RMSEA $=.06,90 \%$ CI .05-.07; CFit $=.15 ;$ SRMR $=.03 ;$ AIC $=21,290 ;$ BIC $=21,490]$. Finally, a second-order model was tested. The model with a second-order construct (Facebook intensity) indicated similarly good model fit compared to the first-order one $[\mathrm{CFI}=.96 ; \mathrm{TLI}=.95 ; \mathrm{RMSEA}=.06,90 \% \mathrm{CI}$ $.05-.07$; CFit $=.12$; SRMR $=.03$; AIC $=21,295$; BIC $=21,486]$. These results suggest that both multidimensional models appear to be adequate.

Finally, the target coefficient value was calculated in order to compare the first-order and the second-order models. The value was .946, indicating the existence of a second-order factor behind the first-order factors. The Facebook use intensity factor explained nearly $95 \%$ of the covariance among the four smaller factors. On the basis of the results, the existence of the hierarchical model including one second-order factor was supported and the second-order model with one hierarchical

Table 3

Comparison of the alternative models of the Multidimensional Facebook Intensity Scale.

\begin{tabular}{|c|c|c|c|c|c|c|c|c|}
\hline Model & CFI & TLI & $\begin{array}{l}\text { RMSEA } \\
{[90 \% \mathrm{CI}]}\end{array}$ & CFit & SRMR & AIC & BIC & $\mathrm{T}$ \\
\hline Study 1 (ESEM) & .98 & .96 & $.05[.03-.06]$ & .52 & .02 & 19,371 & 19,676 & \\
\hline \multicolumn{9}{|l|}{ Study 2 (CFA) } \\
\hline $\begin{array}{l}\text { First-order single } \\
\text { factor model }\end{array}$ & .75 & .69 & $.14[.13-.15]$ & .00 & .08 & 21,898 & 22,067 & \\
\hline $\begin{array}{l}\text { First-order } \\
\text { four-factor model }\end{array}$ & .96 & .95 & $.06[.05-.07]$ & .15 & .03 & 21,290 & 21,490 & \\
\hline $\begin{array}{l}\text { Second-order } \\
\text { four-factor model }\end{array}$ & .96 & .95 & $.06[.05-.07]$ & .12 & .03 & 21,295 & 21,486 & .946 \\
\hline
\end{tabular}

Notes. $\chi^{2}=$ chi-square value; $\mathrm{df}=$ degrees of freedom; $\mathrm{CFI}=$ Comparative Fit Index; $\mathrm{TLI}=$ Tucker-Lewis Index; RMSEA = root-mean-square error of approximation; CFit = RMSEA's test of close fit; SRMR $=$ standardized root mean square residuals; AIC $=$ Akaike Information Criterion; BIC = Bayesian Information Criterion; $\mathrm{T}=$ target coefficient value. 
factor (Facebook intensity) and four smaller factors (persistence, boredom, overuse, and self-expression) was chosen (see Fig. 1).

\section{Study 3}

The aim of this study was to assess the convergent validity of the MFIS by correlating it with hypothetically related constructs. The hypothesized correlations were predicted based on theory and previous research. We expected the dimensions of the MFIS to be positively correlated with the measure of Facebook addiction with the overuse factor having the strongest link, because it assesses quasi problematic behavior related to Facebook use. Furthermore, we expected that nonproblematic Facebook use factors (persistence, self-expression and boredom) are related to Harmonious Facebook Passion, while Facebook overuse is related to Obsessive Facebook Passion. With Harmonious Facebook passion people successfully integrate Facebook use as a part of their self, they accept that it is important to them, and they freely choose to engage in it. For them Facebook is in harmony with other parts of life and takes up a significant but not overwhelming amount of space in their identity. With Obsessive Facebook Passion the person enjoys Facebook use, however, feels forced to engage in it because of internal contingencies. This type of Facebook passion basically controls the person, causes conflicts with other activities and takes an unreasonable amount of space in the individual's identity (Vallerand et al., 2003). Moreover, we expected that online sociability-which refers to the frequency of the user's engagement in Facebook activities (Ross et al., 2009)-as a non-pathologic manifestation of Facebook use is not related to overuse, but mainly to self-expression and Facebook persistence.

We intended to measure the links between MFIS factors and Big Five Inventory (John \& Srivastava, 1999) factors. We expected that selfexpression of Facebook use is related to mainly "social" aspects of personality in terms of Extraversion because talkative, outgoing and sociable individuals are expected to put more emphasis on refining their Facebook profile. Furthermore, based on previous results we expected that overuse-similar to Facebook addiction (Andreassen et al., 2012) -is negatively related to Conscientiousness and positively to Neuroticism. Finally, we did not expect links between Facebook factors and Openness or Agreeableness.

\subsection{Methods}

\subsubsection{Participants}

A total of 550 people were recruited for the study. However, 19 respondents were excluded from the study, because they were underaged. The age of the remaining participants $(\mathrm{N}=531)$ ranged from 18 to $62\left(M_{\text {age }}=23.81 ; S D_{\text {age }}=7.29\right)$ with 393 females $(74 \%)$ and 138 males (26\%). In relation to educational status, out of the 531 participants, 374 (70.4\%) were enrolled into school with 239 (63.9\%) into college or university, 111 (29.7\%) had high school education, $3(0.8 \%)$ had less than high school education and 21 respondents (5.6\%) were in doctoral program.

\subsubsection{Measures}

4.1.2.1. Multidimensional Facebook Intensity Scale. In order to assess its convergent validity, this newly created measurement was administered. Its psychometric properties were described above in details. In the present study-similar to Studies 1 and 2-the Cronbach's alpha values were adequate as well $\left(\alpha_{\text {persistence }}=.79 ; \alpha_{\text {self-expression }}=.74\right.$; $\left.\alpha_{\text {boredom }}=.85 ; \alpha_{\text {overuse }}=.76 ; \alpha_{\text {total }}=.88\right)$.

4.1.2.2. Bergen Facebook Addiction Scale. The Bergen Facebook Addiction Scale was created by Andreassen et al. (2012) with the aim to assess the respondents' level of addiction to Facebook with respect to the six components of addictions (salience, tolerance, mood modification, relapse,

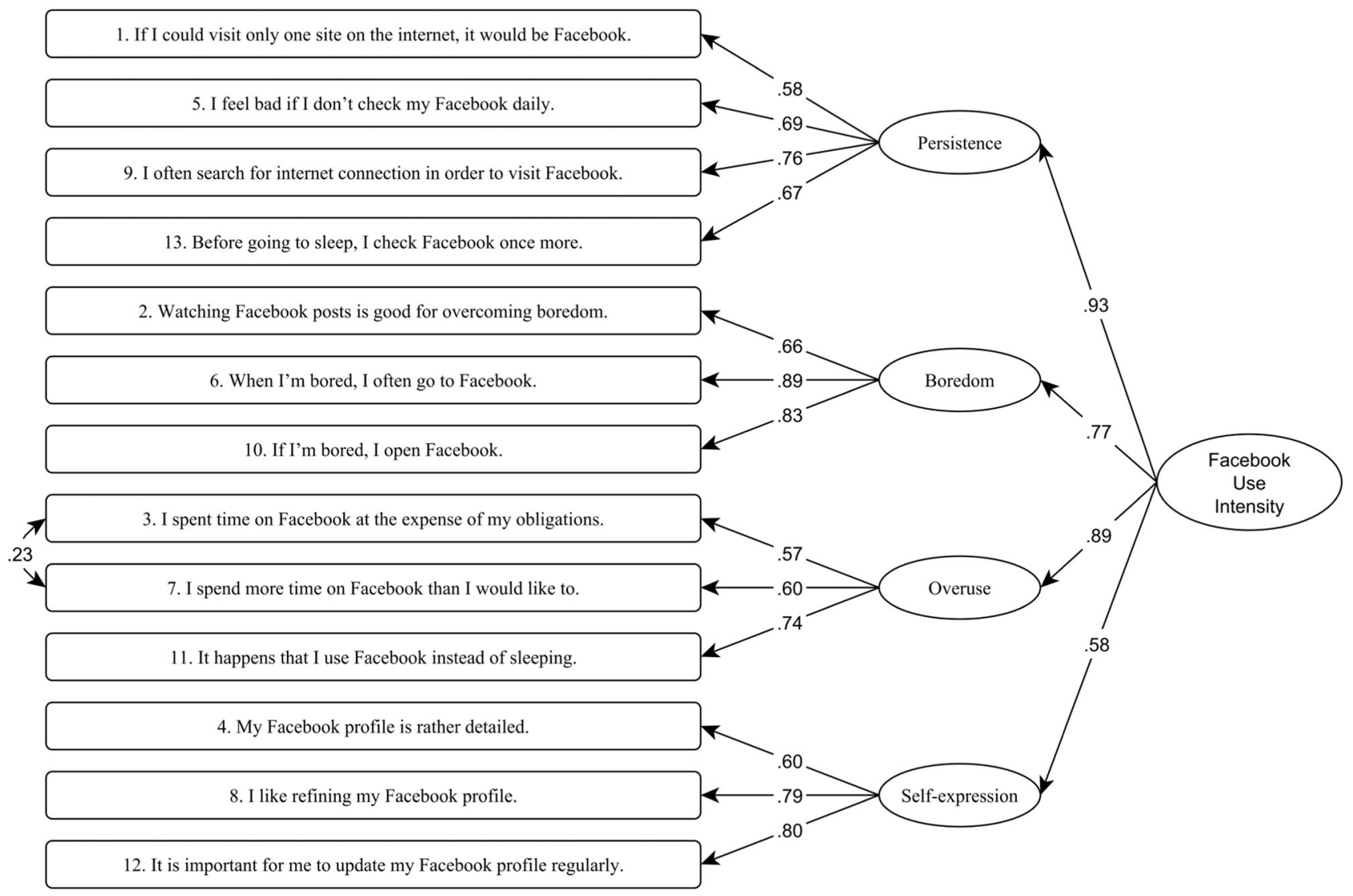

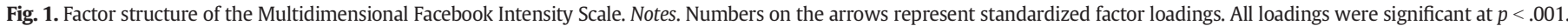


withdrawal, conflict). The scale contains six items representing the six factors and respondents had to answer using a 5 -point scale $(1=$ very rarely; $2=$ rarely; $3=$ sometimes; $4=$ often; $5=$ very often $)$. The Cronbach's alpha value in this study was .78.

4.1.2.3. Online Sociability Scale. Ross et al. (2009) created a Facebook Questionnaire which contained three factors; one of them was the Online Sociability Scale which assessed the individuals engagement in Facebook activities in terms of posting, messaging or commenting on photos on a scale ranging from 1 (more than once daily) to 9 (less than once per year). This scale-similar to the following ones-was translated based on the protocol of Beaton, Bombardier, Guillemin, and Ferraz (2000). The Cronbach's alpha value in this study was low (.57).

4.1.2.4. Facebook Passion Scale. The Passion Scale was developed by Vallerand et al. (2003) who differentiated between two types of passion towards an activity: obsessive and harmonious. The items were modified in order to measure passion related to Facebook use. The scale included 17 items: five for passion criterion (Cronbach's $\alpha$ : .80), six for harmonious (Cronbach's $\alpha$ : .66) and six for obsessive (Cronbach's $\alpha$ : .81 ). Respondents had to indicate their level of agreement with the items using a 7 -point scale ( $1=$ not agree at all; $2=$ very slightly agree; 3 = slightly agree; $4=$ moderately agree; $5=$ mostly agree; $6=$ strongly agree; $7=$ very strongly agree).

4.1.2.5. Big Five Inventory. The Big Five Inventory is a 45 -item scale created by John and Srivastava (1999). A shorter, valid Hungarian version was created by Farkas and Orosz (2013) that contained 15 items and assessed the personality of the respondent by five factors: extraversion, agreeableness, conscientiousness, neuroticism and openness. Respondents had to indicate their level of agreement on a 5-point scale $(1=$ strongly disagree; $2=$ disagree; $3=$ neither agree nor disagree; $4=$ agree; $5=$ strongly agree). The Cronbach's alpha values were the following: $\alpha_{\text {extraversion }}=.80 ; \alpha_{\text {agreeableness }}=.66 ; \alpha_{\text {conscientiousness }}=.71$; $\alpha_{\text {neuroticism }}=.77 ; \alpha_{\text {openness }}=.89$.

\subsubsection{Procedure}

The study was conducted in accordance with the Declaration of Helsinki. All procedures were carried out with the adequate understanding and consent of the participants and with the approval of the related university. The research was conducted using an online questionnaire, the filling out took approximately $15 \mathrm{~min}$. Participants were firstly informed about the content and the aim of the research and were asked to check a box if they agreed to participate. Respondents volunteered for the study and did not receive any compensation for the participation. Their anonymity was also assured.

Concerning the first question of the questionnaire, a thought experiment was exposed to the participants, in which they imagined that they could not use any of the functions of Facebook anymore and could not get information from it neither through their friends, nor other means. They then had to indicate how much money they would expect as a compensation for giving up Facebook use. After, we asked them to give us a detailed explanation as to why they choose that particular amount of money. After this section, they had to fill out the MFIS, the Facebook Passion Scale, the Bergen Facebook Addiction Scale and the Online Sociability Scale, respectively. The following section contained the Big Five Inventory. Finally, respondents were asked to fill out demographic data such as age, gender, level of finished education and current level of education.

\subsubsection{Statistical analysis}

The statistical analyses were performed by the SPSS version 22 . Correlations were evaluated by the Pearson coefficient $r$ (see Table 4); regression analyses were performed to investigate the effects of the predictor variables on the outcome variables. Preliminary analyses were conducted to ensure there was no violation of the assumption of normality, linearity, multicollinearity, and homoscedasticity.

\subsection{Results}

Several regression analyses were performed to assess the criterion validity of the MFIS. In each of the analyses, the four Facebook intensity dimensions were the predictors, whereas the Bergen Facebook Addiction Scale, the Online Sociability Scale, Harmonious and Obsessive Facebook Passion and three dimensions of the Five Factor Model (Extraversion, Conscientiousness, Neuroticism, Agreeableness, and Openness) were entered as outcomes, respectively (see Table 5).

In the first model, the Bergen Facebook Addiction Scale was the outcome variable. After entering the four Facebook intensity factors into the model, the total variance explained was $51.8 \%$. Overuse $(\beta=.46$, $p<.001)$ and persistence $(\beta=.33, p<.001)$ were positively related to the score of the Bergen Facebook Addiction Scale, whereas selfexpression $(\beta=.01, p=.718)$ and boredom $(\beta=.01, p=.769)$ were unrelated to it. It can be hypothesized that the overuse factor would have a strong link with the addiction scale, because both assess problematic use, only the magnitude is different. The link between persistence and Facebook addiction could mean that users who score high on the Bergen Facebook Addiction Scale are considered problematic users who would be unwilling to stop using Facebook, because it is deeply integrated into their lives.

In the second model, the Online Sociability Scale was entered as the outcome. The total variance of the OSS explained by the Facebook intensity factors was $27.2 \%$ with the strongest predictor being self-expression $(\beta=.25, p<.001)$, followed by persistence $(\beta=.23, p<.001)$. Boredom $(\beta=.08, p=.082)$ and overuse $(\beta=.08, p=.086)$ were unrelated to

Table 4

Intercorrelations between the examined variables.

\begin{tabular}{|c|c|c|c|c|c|c|c|c|c|c|c|c|}
\hline & (1) & $(2)$ & (3) & $(4)$ & $(5)$ & (6) & $(7)$ & $(8)$ & (9) & $(10)$ & $(11)$ & $(12)$ \\
\hline (1) Persistence of MFIS & - & & & & & & & & & & & \\
\hline (2) Boredom of MFIS & $.58^{* *}$ & - & & & & & & & & & & \\
\hline (3) Overuse of MFIS & $.60^{* *}$ & $.48^{* *}$ & - & & & & & & & & & \\
\hline (4) Self-expression of MFIS & $.51^{* *}$ & $.36^{* *}$ & $.36^{* *}$ & - & & & & & & & & \\
\hline (5) Bergen Facebook Addiction Scale & $.62^{* *}$ & $.43^{* *}$ & $.67^{* *}$ & $.35^{* *}$ & - & & & & & & & \\
\hline (6) Harmonious Facebook Passion & $.38^{* *}$ & $.27^{* *}$ & .01 & $.35^{* *}$ & $.11^{* *}$ & - & & & & & & \\
\hline (7) Obsessive Facebook Passion & $.63^{* *}$ & $.38^{* *}$ & $.62^{* *}$ & $.42^{* *}$ & $.73^{* *}$ & $23^{* *}$ & - & & & & & \\
\hline (8) Online Sociability Scale & $-.46^{* *}$ & $-.35^{* *}$ & $-.35^{* *}$ & $-.43^{* *}$ & $-.33^{* *}$ & $-.23^{* *}$ & $-.32^{* *}$ & - & & & & \\
\hline (9) Extraversion of Big Five & $.11^{*}$ & .06 & .04 & $.18^{* *}$ & .05 & $.12^{* *}$ & .06 & $-.28^{* *}$ & - & & & \\
\hline (10) Conscientiousness of Big Five & -.06 & -.02 & $-.09^{*}$ & $.11^{*}$ & -.05 & $.23^{* *}$ & .00 & -.06 & $.21^{* *}$ & - & & \\
\hline (11) Neuroticism of Big Five & $-.17^{* *}$ & $-.20^{* *}$ & $-.29^{* *}$ & -.05 & $-.19^{* *}$ & $.14^{* *}$ & $-.17^{* *}$ & .08 & $.10^{*}$ & $.27^{* *}$ & - & \\
\hline (12) Agreeableness of Big Five & $.20^{* *}$ & $.16^{* *}$ & $.26^{* *}$ & $.10^{*}$ & $.26^{* *}$ & -.06 & $.20^{* *}$ & $-.14^{* *}$ & -.06 & $-.20^{* *}$ & $-.27^{* *}$ & - \\
\hline (13) Openness of Big Five & -.07 & $-.09^{*}$ & -.04 & -.02 & -.05 & .06 & -.05 & .01 & -.01 & .07 & .07 & -.04 \\
\hline
\end{tabular}


Table 5

Relationships between MFIS factors, Facebook-related activities and personality traits.

\begin{tabular}{|c|c|c|c|c|c|c|}
\hline & $\mathrm{R}$ & $\mathrm{R}^{2}$ & B & SE & $\beta$ & $\mathrm{t}$ \\
\hline $\begin{array}{r}\text { Bergen Facebook } \\
\text { Addiction Scale }\end{array}$ & .72 & .52 & & & & \\
\hline Persistence & & & $.23[.17-.29]$ & .03 & $.33^{* * *}$ & 7.52 \\
\hline Boredom & & & $.01[-.04$ to .06$]$ & .03 & .01 & .29 \\
\hline Overuse & & & $.29[.24-.34]$ & .02 & $.46^{* * *}$ & 12.06 \\
\hline Self-expression & & & $.01[-.05$ to .07$]$ & .03 & .01 & .36 \\
\hline Online Sociability Scale & .52 & .27 & & & & \\
\hline Persistence & & & $.30[.16-.43]$ & .07 & $.23^{* * *}$ & 4.36 \\
\hline Boredom & & & $.10[-.01$ to .22$]$ & .06 & .08 & 1.74 \\
\hline Overuse & & & $.09[-.01$ to .12$]$ & .05 & .08 & 1.72 \\
\hline Self-expression & & & $.40[.27-.53]$ & .07 & $.23^{* * *}$ & 5.92 \\
\hline $\begin{array}{l}\text { Harmonious Facebook } \\
\text { Passion }\end{array}$ & .53 & .28 & & & & \\
\hline Persistence & & & $.42[.32-.52]$ & .05 & $.42^{* * *}$ & 7.91 \\
\hline Boredom & & & $.14[.05-.23]$ & .05 & $.14^{* *}$ & 3.01 \\
\hline Overuse & & & $-.36[-.44$ to .28$]$ & .04 & $-.40^{* * *}$ & -8.50 \\
\hline Self-expression & & & $.28[.18-.39]$ & .05 & $.23^{* * *}$ & 5.33 \\
\hline $\begin{array}{l}\text { Obsessive Facebook } \\
\text { Passion }\end{array}$ & .71 & .50 & & & & \\
\hline Persistence & & & $.28[.21-.35]$ & .03 & $.37^{* * * *}$ & 8.25 \\
\hline Boredom & & & $-.05[-.11$ to .01$]$ & .03 & $-.07^{* * *}$ & -1.75 \\
\hline Overuse & & & $.27[.22-.32]$ & .03 & $.39^{* * *}$ & 9.98 \\
\hline Self-expression & & & $.12[.05-.18]$ & .03 & $.12^{* *}$ & 3.40 \\
\hline Extraversion & .18 & .03 & & & & \\
\hline Persistence & & & $.05[-.06-.16]$ & .06 & .05 & .85 \\
\hline Boredom & & & $-.01[-.11$ to .09$]$ & .05 & -.01 & -.20 \\
\hline Overuse & & & $-.04[-.13$ to .05$]$ & .05 & -.05 & -.81 \\
\hline Self-expression & & & $.20[.08-.31]$ & .06 & $.17^{* *}$ & 3.42 \\
\hline Conscientiousness & .31 & .10 & & & & \\
\hline Persistence & & & $.03[-07$ to .12$]$ & .05 & .03 & .54 \\
\hline Boredom & & & $-.09[-.17$ to -.01$]$ & .04 & $-.11^{*}$ & 2.18 \\
\hline Overuse & & & $-.21[-.29$ to -.14$]$ & .04 & $-.29^{* * *}$ & -5.51 \\
\hline Self-expression & & & $.08[-.02$ to .18$]$ & .05 & .08 & 1.65 \\
\hline Neuroticism & .27 & .07 & & & & \\
\hline Persistence & & & $.05[-.06$ to .16$]$ & .06 & .05 & .83 \\
\hline Boredom & & & $.03[-.07$ to .12$]$ & .05 & .03 & .55 \\
\hline Overuse & & & $.19[.10-.27]$ & .04 & $.22^{* * *}$ & 4.22 \\
\hline Self-expression & & & $-.01[-.12$ to .10$]$ & .06 & -.01 & -.24 \\
\hline Agreeableness & .20 & .04 & & & & \\
\hline Persistence & & & $-.09[-.17$ to -.00$]$ & .04 & $-.13^{*}$ & -2.06 \\
\hline Boredom & & & $.02[-.05$ to .09$]$ & .04 & .03 & .55 \\
\hline Overuse & & & $-.06[-.13$ to .01$]$ & .03 & -.10 & -1.80 \\
\hline Self-expression & & & $.17[.09-.26]$ & .04 & $.20^{* * *}$ & 4.04 \\
\hline Openness & .09 & .01 & & & & \\
\hline Persistence & & & $-.05[-.17$ to .08$]$ & .06 & -.05 & -.73 \\
\hline Boredom & & & $-.08[-.18$ to .03$]$ & .06 & -.07 & -1.36 \\
\hline Overuse & & & $.01[-.09$ to .11$]$ & .05 & .01 & .21 \\
\hline Self-expression & & & $.03[-.09$ to .16$]$ & .06 & .02 & .51 \\
\hline
\end{tabular}

${ }^{*} p<.05$.

** $p<.01$.

*** $p<.001$.

the OSS. Sharing and posting content can very possibly be another form of self-expression (besides the user's own profile).

In the third model, the Harmonious Facebook Passion was the outcome. The total variance explained by the Facebook factors was $27.6 \%$. Three of the predictors were positively related to Harmonious Facebook passion [persistence $(\beta=.42, p<.001)$, self-expression $(\beta=.23, p<$ $.001)$, boredom $(\beta=.14, p<.01)]$, whereas overuse $(\beta=-.40$, $p<.001$ ) was negatively related to it. These results suggest that those users who have Harmonious Facebook Passion report the nonproblematic aspects of Facebook. Furthermore, the negative link between Harmonious Facebook Passion and the overuse factor of the MFIS indicate that these users probably do not have problems stemming from their Facebook usage.

In the fourth model, the outcome was the Obsessive Facebook Passion. The four Facebook dimensions explained $49.7 \%$ of the total variance of Obsessive Facebook Passion. Overuse was the strongest predictor $(\beta=.39, p<.001)$, followed by persistence $(\beta=.37, p<$ $.001)$, and self-expression $(\beta=.12, p<.001)$. Boredom $(\beta=-.07$, $p=.080$ ) was not related to Obsessive Facebook Passion. In this case besides the problematic aspects of Facebook use, the nonproblematic aspects are also related to Obsessive Passion. However, in line with our expectations, the strongest predictor of Obsessive Passion was the overuse. Considering the complementary, relatively strong relationships between Harmonious and Obsessive Passion and overuse, the Dualistic Model of Passion (Vallerand et al., 2003) appears to be an adequate tool to distinguish problematic and nonproblematic aspects of Facebook use.

In the following section, the five dimensions of the BFI were entered as the outcome variables. In the case of Extraversion, the total variance explained was $3.3 \%$. Only self-expression $(\beta=.17, p<.001)$ was positively related to extraversion, the other three factors were not: persistence $(\beta=.05, p=.392)$, overuse $(\beta=-.04, p=.417)$ and boredom $(\beta=-.01, p=.839)$. These results are in line with our hypothesis: self-expression on Facebook is positively linked to Extraversion.

In the sixth model, Conscientiousness was the outcome. The total variance explained by the predictors is $9.8 \%$ with the strongest predictor being overuse $(\beta=-.29, p<.001)$, followed by boredom $(\beta=-.11$, $p<.05)$, while self-expression $(\beta=.08, p=.100)$ and persistence $(\beta=.03, p=.590)$ were unrelated. Both of the related predictors are negatively linked to Conscientiousness. These results are in line with our assumptions: those who are lazy and less conscientious are inclined in overusing Facebook, whereas the link between Facebook boredom and Conscientiousness appears to be relatively weak.

In the seventh regression model, Neuroticism was entered as the outcome. The total variance explained by this model was $7.2 \%$. Only overuse $(\beta=.22, p<.001)$ was positively related to Neuroticism, whereas persistence $(\beta=.05, p=.409)$, boredom $(\beta=.03, p=.582)$ and self-expression $(\beta=-.01, p=.810)$ were unrelated. Similar to the Conscientiousness, Neuroticism is positively related to overuse but unrelated to the non-problematic aspects of Facebook use. It is both in line with previous results (Andreassen et al., 2012) and with our hypothesis.

Although there were no hypotheses regarding Agreeableness and Openness, both of these Big Five dimensions were entered as outcome variables as well. Regarding Agreeableness, the total explained variance by the MFIS dimensions was $4 \%$ with self-expression $(\beta=$ $.20, p<.01)$ and persistence $(\beta=-.13, p<.05)$ being significant predictors, whereas overuse $(\beta=-.10, p=.073)$ and boredom $(\beta=$ $.03, p=.583$ ) were not related to Agreeableness. In the case of Openness, none of the MFIS dimensions were related to this Big Five dimension.

\subsubsection{The value of Facebook}

Participants indicated how much Facebook is worth for them. The average amount of money they could consider as a compensation for losing Facebook from their lives was 5284 USD (SD = 7689 USD). The amount was positively correlated with persistence $(r=.35, p<$ $.001)$, overuse $(r=.16, p<.001)$, self-expression $(r=.23, p<$ $.001)$, and boredom $(r=.19, p<.01)$ factors. There were many reasons why respondents would ask a great amount of money as a compensation giving up Facebook. A 46 year old female respondent said the following: "Because giving Facebook up for me is equal to giving up social relationships for the rest of my life". A 27 year old female respondent explained it differently: "I'm applying for jobs currently. In a thematic group people indicate a new job opportunity before officially published by the company. Such information is priceless". A 22 year old male student claimed that the Facebook is very important to him because of the following reasons: "I get a whale of information and notes for my studies which are only available here on Facebook". These quotes and results suggest that Facebook is valuable for its users, and interestingly it appears to be more valuable for those who have high persistence score compared to those who have high overuse scores. 


\section{Study 4}

In Study 4 our goal was to demonstrate the incremental validity of the MFIS. We supposed that MFIS can explain an additional amount of variance of the two most frequent Facebook behaviors ("liking" and "posting") over and above Ellison et al.'s (2007) Facebook Intensity Scale. We assume that the frequency of "posting" and "liking" are good representations of the behavioral consequences of high Facebook intensity and they are not mentioned explicitly in either scales.

\subsection{Methods}

\subsubsection{Participants}

The sample of Study 1 was used in order to measure incremental validity.

\subsubsection{Measures}

5.1.2.1. Facebook Intensity Scale. Facebook Intensity Scale (FIS; Ellison et al., 2007) assesses self-reported information regarding the extent to which participants engage in Facebook activities and measures the involvement in Facebook use. The FIS was translated to Hungarian following Beaton et al.'s (2000) protocol. The scale contains eight items $(\alpha=0.79)$ with three different types of scales (for details see Ellison et al., 2007). The scale has good construct validity and it is reliable in terms of their internal consistency.

\subsubsection{Multidimensional Facebook Intensity Scale. See Study 1, 2, 3.}

5.1.2.3. Self-reported Facebook behavior. Two items were added in order to measure behavioral aspects of Facebook Intensity: "I post daily." and "I 'like' daily.". The response scale was identical to the MFIS scaling.

\subsection{Results}

A hierarchical multiple regression analysis was conducted to evaluate how well Ellison et al.'s (2007) FIS and the MFIS predicts selfreported liking and posting behaviors. The predictors were separated into two distinct sets. Block 1 contained Ellison et al.'s Facebook Intensity scores, while Block 2 contained the MFIS factors.

Both Facebook Intensity Scales were related significantly to liking $\left[\mathrm{R}^{2}=.33\right.$, adjusted $\left.\mathrm{R}^{2}=.32, \mathrm{~F}(5,503)=49.55, p<.001\right]$. Facebook intensity as a control predictor $(\beta=.24 ; p<.001)$ accounted for a significant amount of liking frequency variation $\left[\mathrm{R}^{2}\right.$ change $\left.=.24, p<.001\right]$, whereas three MFIS dimensions $\left[\beta_{\text {boredom }}=.11 ; p=.013 ; \beta_{\text {self-expression }}=\right.$ $.23 ; p<.001 ; \beta_{\text {peristence }}=.12 ; p<.022$ ] accounted for a significant amount of variance of liking frequency $\left[\mathrm{R}_{\text {change }}^{2}=.09, \mathrm{~F}_{\text {change }} p=.005\right]$. After controlling for the effects of Facebook Intensity scores, MFIS dimensions made a significant, independent contribution to the variance in liking frequency.

Only MFIS related significantly to the frequency of posting $\left[\mathrm{R}^{2}=\right.$ .25 , adjusted $\left.\mathrm{R}^{2}=.24, \mathrm{~F}(5,503)=33.34, p<.001\right]$. In the final model, Facebook intensity as a control predictor $(\beta=.03 ; p=.604)$ not accounted for a significant amount of posting frequency variation $\left[\mathrm{R}_{\text {change }}^{2} .10, p<.001\right]$, whereas three MFIS dimensions $\left[\beta_{\text {overuse }}=.11 ; p=.015 ; \beta_{\text {self-expression }}=.37 ; p<.001 ; \beta_{\text {persistence }}=\right.$ $.12 ; p<.024]$ accounted for a significant amount of variance of posting frequency $\left[\mathrm{R}^{2}\right.$ change $\left.=.15, \mathrm{~F}_{\text {change }} p<.001\right]$. After controlling for the effects of Facebook Intensity scores, MFIS dimensions made a significant, independent contribution to the variance in posting frequency. In sum, concerning both liking and posting-as the two most important active Facebook behaviors-results suggest that MFIS have an incremental validity compared to the original Facebook Intensity Scale of Ellison et al. (2007).

\section{General discussion}

People differ in their Facebook use. We intended to grasp individual differences in how people use it in the new era of Facebook. In Studies 1 and 2, we created a short, valid, and reliable Multidimensional Facebook Intensity Scale that is able to grasp the most salient aspects of Facebook use. In Study 3, we aimed to examine its convergent validity. In Study 4, we measured the incremental validity. We identified four factors: persistence, boredom, overuse, and self-expression.

The first factor, Facebook persistence, grasps the strength of the emotional bond between Facebook and the user. Those individuals who score high on this scale check Facebook before going to bed, or often looking for Internet connection in order to gain access to Facebook. The persistence factor of Facebook use is positively related to Facebook addiction. We assume that persistent Facebook use does not necessarily belong to problematic Facebook use, but it can be interpreted as a prerequisite of Facebook addiction. However, Facebook persistence is linked to harmonious and obsessive passion, as well. This result suggests that persistence cannot only lead to obsessive passion and addiction towards Facebook, but it can lead to harmonious passion which means that Facebook use is not necessarily in conflict with other important aspects of the individual's life. Facebook persistence is positively related to online sociability, liking, and posting behavior. It means that if a person feels a strong attachment to Facebook use; it can lead to more intensive Facebook use in terms of posting, messaging, or viewing her/his profile more frequently. Finally, those who have high scores on this scale evaluate Facebook more valuably. The link between the perceived financial value of Facebook and persistence was even stronger than its link with overuse which reflects on the manifested emotional bond towards Facebook.

The second factor, boredom, refers to the motivation to use Facebook in order to relieve boredom (e.g. Lampe et al., 2008; Pempek et al., 2009). It can be assumed that the more a user is bored, the more intensively she/he uses Facebook, because it offers plenty of different stimuli that could be used as a coping tool in low arousal and affective valence situations. The use of Facebook in order to relieve boredom is unrelated to Facebook addiction, but negatively related to Obsessive Facebook Passion and positively to Harmonious Facebook Passion. According to our results, being bored and using Facebook leads to more frequent liking behavior, but does not lead to more excessive posting, commenting or profile viewing in terms of online sociability.

The third factor, overuse, is related to the excessive use and addictive dimensions Facebook as previously assessed by Andreassen et al. (2012). While both the Bergen Facebook Addiction Scale and the overuse factor of the MFIS assess problematic aspects of using Facebook intensively, the difference is in the magnitude of problems: while the overuse factor refers to smaller problems (i.e. spending time on Facebook at the expense of sleeping time), the Bergen Addiction Scale was designed to measure pathological aspects. The Facebook overuse is negatively related to harmonious passion and positively to obsessive passion. These results are in line with previous studies (e.g. Lafreniere, Vallerand, Donahue, \& Lavigne, 2009; Stoeber, Harvey, Ward, \& Childs, 2011), in which problematic activities were related to obsessive passion while non-problematic activities were linked to harmonious passion. In terms of personality, Neuroticism is positively related to Facebook overuse and negatively related to Conscientiousness. These results are in line with Andreassen et al.'s (2012) results. The positive relationship between Neuroticism and Facebook overuse is also reasonable: those individuals who feel less emotional stability can use Facebook in an exaggerated way in order to find social support, positive feedbacks or reinforcement through others. Finally, this factor is positively related to self-reported posting behavior.

The fourth and final factor, Facebook self-expression, fulfills the need to present ourselves, ideas, thoughts and tastes to the world via Facebook. This factor is related to the profile-related activities already explored in previous studies (Aladwani, 2014; Alhabash et al., 2012; Christofides et al., 2009; Mehdizadeh, 2010; Strano, 2008). Recent 
results (Correa, Hinsley, \& de Zúniga, 2010; Ryan \& Xenos, 2011; Wilson, Fornasier, \& White, 2010) have suggested that Extraversion is positively linked to Facebook use. In the third study we have also found link between Extraversion and self-expression on Facebook which can be explained by the following way: if an individual is more extroverted, she/he will refine her/his profile more frequently and this profile page will be more detailed. This factor is positively related to both liking and posting behavior. Furthermore, the self-expression factor of MFIS is not related to Facebook addiction, which means that if an individual refines his/her profile page, it does not necessarily go hand in hand with addiction. However, self-expression is positively related to obsessive and Harmonious Facebook Passion, as well. These results suggest that obsessive passion towards Facebook includes activities related to self-expression, but the lack of relationship with addiction and the weak link with overuse reflects on the non-problematic nature of the self-expression measured with MFIS.

On April 15, 2015, Facebook has an objective enterprise value around 218 billion dollars on the stock market (Yahoo Finance, 2015). However, if we estimated the value of Facebook from the perspective of Hungarian users, its price would be twenty-four times higher. It is valuable not only for addicted individuals, but it is valuable also for those who use it in a not exaggerated way for work, studying, entertainment, communication or just wasting time on the morning train. However, there are salient difference between individuals concerning persistence, self-expression, coping with boredom, and overuse.

There are limitations with the present research that have to be mentioned. Besides the mainly cross-sectional studies, a longitudinal design could be fruitful in examining how different events affect one's Facebook use. Second, the samples were not representative and the used questionnaires were self-reported by nature, thus are prone to bias. In the future, more objective methods could be used to precisely assess Facebook behavior while respecting the person's privacy. Third, all the items were positively keyed, making them vulnerable to acquiescence bias. The extension of the MFIS could incorporate reverse-coded items as well. Furthermore, additional research could examine the validity of the MFIS in different populations, among elderly or younger Facebook users. Finally, a further implicit measure based on these dimensions could reflect on hidden attitudes towards Facebook use. Despite these limitations, the MFIS appears to be a valuable tool in measuring one's Facebook use. The questionnaire has good psychometric properties and it is able to measure both problematic and nonproblematic aspects of Facebook use simultaneously.

\section{Conclusion}

The present research demonstrated that the Multidimensional Facebook Intensity Scale is able to grasp the main facets of Facebook use, namely persistence, boredom, overuse, and self-expression. This short scale has good psychometric properties, reliability and temporal stability. It can separate problematic and non-problematic aspects of Facebook use. Facebook intensity is related to the subjective value of Facebook. The differentiated Facebook intensity facets can predict better frequent Facebook-related behaviors as liking and posting than previous measures.

\section{Acknowledgments}

GO was supported by the Hungarian Research Fund (NKFI PD 106027 and PD 116686) and Momentum (0183-13 502). We are very grateful to the students of University of Szeged for their substantial contribution regarding item construction.

\section{References}

Aghazamani, A. (2010). How do university students spend their time on Facebook? An exploratory study. Journal of American Science, 6(12), 730-735.
Aladwani, A. M. (2014). Gravitating towards Facebook (GoToFB): What it is? And how can it be measured? Computers in Human Behavior, 33, 270-278. http://dx.doi.org/ 10.1016/j.chb.2014.01.005.

Alhabash, S., Park, H., Kononova, A., Chiang, Y. -H., \& Wise, K. (2012). Exploring the motivations of Facebook use in Taiwan. Cyberpsychology, Behavior, and Social Networking, 15(6), 304-311. http://dx.doi.org/10.1089/cyber.2011.0611.

Andreassen, C. S., Torsheim, T., Brunborg, G. S., \& Pallesen, S. (2012). Development of a Facebook Addiction Scale. Psychological Reports, 110(2), 501-517. http://dx.doi.org/ 10.2466/02.09.18.PR0.110.2.501-517.

Asparouhov, T., \& Muthén, B. (2009). Exploratory structural equation modeling. Structural Equation Modeling: A Multidisciplinary Journal, 16(3), 397-438. http://dx.doi.org/10. 1080/10705510903008204.

Beaton, D. E., Bombardier, C., Guillemin, F., \& Ferraz, M. B. (2000). Guidelines for the process of cross-cultural adaptation of self-report measures. Spine, 25(24), 3186-3191.

Bijari, B., Javadinia, S. A., Erfanian, M., Abedini, M., \& Abassi, A. (2013). The impact of virtual social networks on students' academic achievement in Birjand University of Medical Sciences in East Iran. Procedia - Social and Behavioral Sciences, 83, 103-106. http://dx.doi.org/10.1016/j.sbspro.2013.06.020.

Brown, T. A. (2006). Confirmatory factor analysis for applied research. Methodology in the social sciences. New York: Guilford Press.

Cavallo, D. N., Tate, D. F., Ries, A. V., Brown, J. D., DeVellis, R. F., \& Ammerman, A. S. (2012). A social media-based physical activity intervention. American Journal of Preventive Medicine, 43(5), 527-532. http://dx.doi.org/10.1016/j.amepre.2012.07.019.

Christofides, E., Muise, A., \& Desmarais, S. (2009). Information disclosure and control on Facebook: Are they two sides of the same coin or two different processes? Cyberpsychology \& Behavior, 12(3), 341-345. http://dx.doi.org/10.1089/cpb.2008. 0226.

Correa, T., Hinsley, A. W., \& de Zúniga, H. G. (2010). Who interacts on the Web?: The intersection of users' personality and social media use. Computers in Human Behavior, 26(2), 247-253. http://dx.doi.org/10.1016/j.chb.2009.09.003.

Ellison, N. B., Steinfield, C., \& Lampe, C. (2007). The benefits of Facebook "friends": Social capital and college students' use of online social network sites. Journal of ComputerMediated Communication, 12(4), 1143-1168. http://dx.doi.org/10.1111/j.1083-6101. 2007.00367.x

Farkas, D., \& Orosz, G. (2013). The link between ego-resiliency and changes in Big Five traits after decision making: The case of extraversion. Personality and Individual Differences, 55(4), 440-445. http://dx.doi.org/10.1016/j.paid.2013.04.003.

Giannakos, M. N., Chorianopoulos, K., Giotopoulos, K., \& Vlamos, P. (2013). Using Facebook out of habit. Behaviour E' Information Technology, 32(6), 594-602. http:// dx.doi.org/10.1080/0144929X.2012.659218.

Glynn, C. J., Huge, M. E., \& Hoffman, L. H. (2012). All the news that's fit to post: A profile of news use on social networking sites. Computers in Human Behavior, 28(1), 113-119. http://dx.doi.org/10.1016/j.chb.2011.08.017.

Hu, L., \& Bentler, P. M. (1999). Cutoff criteria for fit indexes in covariance structure analysis: Conventional criteria versus new alternatives. Structural Equation Modeling: A Multidisciplinary Journal, 6(1), 1-55. http://dx.doi.org/10.1080/10705519909540118.

John, O. P., \& Srivastava, S. (1999). The Big Five trait taxonomy: History, measurement, and theoretical perspectives. In L.A. Pervin, \& O. P. John (Eds.), Handbook of personality: Theory and research (pp. 102-138) (2nd ed.). New York: Guilford Press.

Joinson, A. N. (2008). Looking at, looking up or keeping up with people? In M. Czerwinski, A. Lund, \& D. Tan (Eds.), Proceeding of the twenty-sixth annual CHI conference (pp. 1027-1036). http://dx.doi.org/10.1145/1357054.1357213.

Kalpidou, M., Costin, D., \& Morris, J. (2011). The relationship between Facebook and the well-being of undergraduate college students. Cyberpsychology, Behavior, and Social Networking, 14(4), 183-189. http://dx.doi.org/10.1089/cyber.2010.0061.

Kirschner, P. A., \& Karpinski, A. C. (2010). Facebook and academic performance. Computers in Human Behavior, 26(6), 1237-1245. http://dx.doi.org/10.1016/j.chb.2010.03.024.

Kwan, G. C. E., \& Skoric, M. M. (2013). Facebook bullying: An extension of battles in school. Computers in Human Behavior, 29(1), 16-25. http://dx.doi.org/10.1016/j.chb. 2012.07.014.

Lafreniere, M. A. K., Vallerand, R. J., Donahue, E. G., \& Lavigne, G. L. (2009). On the costs and benefits of gaming: The role of passion. Cyberpsychology \& Behavior, 12(3), 285-290. http://dx.doi.org/10.1089/cpb.2008.0234.

Lampe, C., Ellison, N. B., \& Steinfield, C. (2008). Changes in use and perception of Facebook. In B. Begole, \& D. W. McDonald (Eds.), The ACM 2008 conference (pp. 721-730). http://dx.doi.org/10.1145/1460563.1460675.

Marsh, H. W., \& Hocevar, D. (1985). Application of confirmatory factor analysis to the study of self-concept: First- and higher order factor models and their invariance across groups. Psychological Bulletin, 97(3), 562-582. http://dx.doi.org/10.1037/ 0033-2909.97.3.562.

Masur, P. K., Reinecke, L., Ziegele, M., \& Quiring, O. (2014). The interplay of intrinsic need satisfaction and Facebook specific motives in explaining addictive behavior on Facebook. Computers in Human Behavior, 39, 376-386. http://dx.doi.org/10.1016/j. chb.2014.05.047.

Mazman, S. G., \& Usluel, Y. K. (2010). Modeling educational usage of Facebook. Computers E' Education, 55(2), 444-453. http://dx.doi.org/10.1016/j.compedu.2010.02.008.

Mehdizadeh, S. (2010). Self-presentation 2.0: Narcissism and self-esteem on Facebook. Cyberpsychology, Behavior, and Social Networking, 13(4), 357-364. http://dx.doi.org/ 10.1089/cyber.2009.0257.

Muthén, L. K., \& Muthén, B. O. (1998-2012). Mplus user's guide (Seventh ed.). Los Angeles, CA: Muthén \& Muthén.

Nunnally, J. C. (1978). Psychometric theory. (2d ed.). McGraw-Hill series in psychology. New York: McGraw-Hill.

Pempek, T. A., Yermolayeva, Y. A., \& Calvert, S. L. (2009). College students' social networking experiences on Facebook. Journal of Applied Developmental Psychology, 30(3), 227-238. http://dx.doi.org/10.1016/j.appdev.2008.12.010. 
Rosen, L. D., Carrier, L. M., \& Cheever, N. A. (2013). Facebook and texting made me do it: Media-induced task-switching while studying. Computers in Human Behavior, 29(3), 948-958. http://dx.doi.org/10.1016/j.chb.2012.12.001.

Ross, C., Orr, E. S., Sisic, M., Arseneault, J. M., Simmering, M. G., \& Orr, R. R. (2009). Personality and motivations associated with Facebook use. Computers in Human Behavior, 25(2), 578-586. http://dx.doi.org/10.1016/j.chb.2008.12.024.

Ryan, T., \& Xenos, S. (2011). Who uses Facebook? An investigation into the relationship between the Big Five, shyness, narcissism, loneliness, and Facebook usage. Computers in Human Behavior, 27(5), 1658-1664. http://dx.doi.org/10.1016/j.chb. 2011.02.004.

Sheldon, P. (2008). The relationship between unwillingness-to-communicate and students' Facebook use. Journal of Media Psychology, 20(2), 67-75. http://dx.doi.org/10. 1027/1864-1105.20.2.67.

Smock, A. D., Ellison, N. B., Lampe, C., \& Wohn, D. Y. (2011). Facebook as a toolkit: A uses and gratification approach to unbundling feature use. Computers in Human Behavior, 27(6), 2322-2329. http://dx.doi.org/10.1016/j.chb.2011.07.011.

Stoeber, J., Harvey, M., Ward, J. A., \& Childs, J. H. (2011). Passion, craving, and affect in online gaming: Predicting how gamers feel when playing and when prevented from playing. Personality and Individual Differences, 51(8), 991-995. http://dx.doi.org/10. 1016/j.paid.2011.08.006.

Strano, M. M. (2008). User descriptions and interpretations of self-presentation through Facebook profile images. Cyberpsychology: Journal of Psychosocial Research on Cyberspace, 2(2) (Retrieved from http://www.cyberpsychology.eu/view.php? cisloclanku $=2008110402$ \&article $=5)$.

Tosun, L. P. (2012). Motives for Facebook use and expressing "true self" on the Internet. Computers in Human Behavior, 28(4), 1510-1517. http://dx.doi.org/10.1016/j.chb. 2012.03.018
Vallerand, R. J., Blanchard, C., Mageau, G. A., Koestner, R., Ratelle, C., Léonard, M., Marsolais, J. (2003). Les passions de l'âme: On obsessive and harmonious passion. Journal of Personality and Social Psychology, 85(4), 756-767. http://dx.doi.org/10. 1037/0022-3514.85.4.756.

Wilson, K., Fornasier, S., \& White, K. M. (2010). Psychological predictors of young adults' use of social networking sites. Cyberpsychology, Behavior, and Social Networking, 13(2), 173-177. http://dx.doi.org/10.1089/cyber.2009.0094.

Yang, C. C., \& Brown, B. B. (2013). Motives for using Facebook, patterns of Facebook activities, and late adolescents' social adjustment to college. Journal of Youth and Adolescence, 42(3), 403-416. http://dx.doi.org/10.1007/s10964-012-9836-x.

\section{Web references}

Duggan, M., Ellison, N. B., Lampe, C., Lenhart, A., \& Madden, M. (2015r). Social Media Update 2014. http://www.pewinternet.org/2015/01/09/social-media-update-2014/ (Retrieved from the Pew Research Center on April 15, 2015)

eMarketer (2015r). http://www.emarketer.com/Article/Facebooks-US-Ad-RevenuesOutpace-Users-Average-Daily-Time-Spent-on-Site/1011215 (Retrieved on April 15, 2015)

Facebook (2015r). Company info. http://newsroom.fb.com/company-info/ (Retrieved on April 15, 2015)

Yahoo Finance (2015r). Facebook, Inc. (FB) key statistics. http://finance.yahoo.com/q/ks? $\mathrm{s}=\mathrm{FB}+$ Key + Statistics (Retrieved on April 15, 2015) 